PREPARED FOR THE U.S. DEPARTMENT OF ENERGY, UNDER CONTRACT DE-AC02-76CH03073

PPPL-3731

PPPL-3731

UC-70

Ferroelectric Cathodes in Transverse Magnetic Fields

by

Alexander Dunaevsky, Yevgeny Raitses, and Nathaniel J. Fisch

July 2002

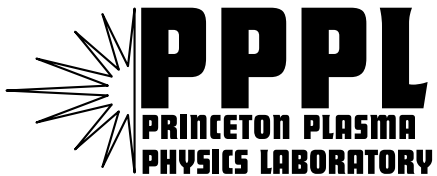

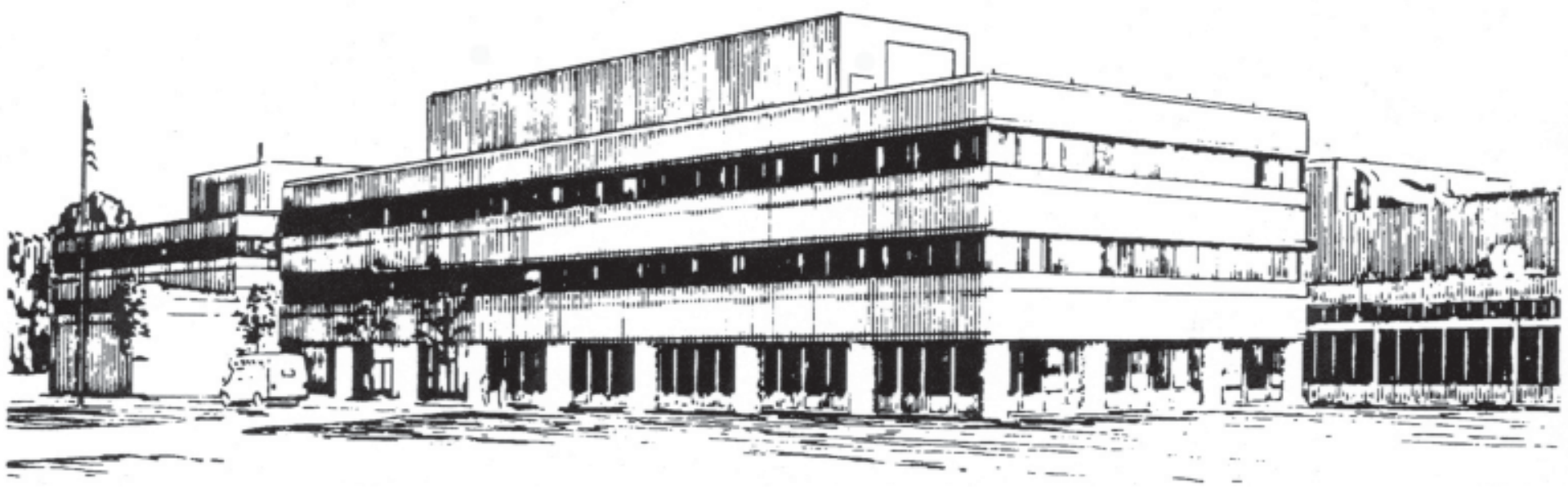

PRINCETON PLASMA PHYSICS LABORATORY PRINCETON UNIVERSITY, PRINCETON, NEW JERSEY 


\section{PPPL Reports Disclaimer}

This report was prepared as an account of work sponsored by an agency of the United States Government. Neither the United States Government nor any agency thereof, nor any of their employees, makes any warranty, express or implied, or assumes any legal liability or responsibility for the accuracy, completeness, or usefulness of any information, apparatus, product, or process disclosed, or represents that its use would not infringe privately owned rights. Reference herein to any specific commercial product, process, or service by trade name, trademark, manufacturer, or otherwise, does not necessarily constitute or imply its endorsement, recommendation, or favoring by the United States Government or any agency thereof. The views and opinions of authors expressed herein do not necessarily state or reflect those of the United States Government or any agency thereof.

\section{Availability}

This report is posted on the U.S. Department of Energy's Princeton Plasma Physics Laboratory Publications and Reports web site in Fiscal Year 2002. The home page for PPPL Reports and Publications is: http://www.pppl.gov/pub_report/

DOE and DOE Contractors can obtain copies of this report from:

U.S. Department of Energy

Office of Scientific and Technical Information

DOE Technical Information Services (DTIS)

P.O. Box 62

Oak Ridge, TN 37831

Telephone: (865) 576-8401

Fax: (865) 576-5728

Email: reports@adonis.osti.gov

This report is available to the general public from:

National Technical Information Service

U.S. Department of Commerce

5285 Port Royal Road

Springfield, VA 22161

Telephone: 1-800-553-6847 or

(703) 605-6000

Fax: (703) 321-8547

Internet: http://www.ntis.gov/ordering.htm 


\title{
Ferroelectric cathodes in transverse magnetic fields
}

\author{
Alexander Dunaevsky, Yevgeny Raitses, and Nathaniel J. Fisch \\ Princeton Plasma Physics Laboratory, Princeton University, P.O.Box 451, Princeton, NJ
}

08543, USA

Experimental investigations of a planar ferroelectric cathode in a transverse magnetic field up to $3 \mathrm{kGs}$ are presented. It is shown that the transverse magnetic field affects differently the operation of ferroelectric plasma cathodes in bright and dark modes in vacuum. In the bright mode, when the surface plasma is formed, the application of the transverse magnetic field leads to an increase of the surface plasma density. In the dark mode, the magnetic field inhibits the development of electron avalanches along the surface, as it does similarly in other kinds of surface discharges in the pre-breakdown mode.

52.50.Dg, 52.80.-s, 77.90.+k 
During the last decade, the phenomenon of strong ferroelectric emission has been studied widely. It has been shown that the application of a driving pulse of a few $\mathrm{kV}$, between solid rear and patterned front electrodes, which cover ferroelectric ceramics, results in electron emission from the side of the front electrode ${ }^{1}$. The current density of this electron emission varies from tens of $\mathrm{mA}$ to hundreds $\mathrm{A}$ per $\mathrm{cm}^{2}$, depending on various experimental conditions: the polarity, the amplitude, and the shape of the driving pulse; the pattern geometry and the composition of the front electrode; the thickness and the composition of the ferroelectric ceramics: and the amplitude, the duration, and the time delay of application of the extracting voltage ${ }^{2}$.

In recent publications ${ }^{3,4,5,6}$, dark and bright modes were distinguished from the electron emission observed from ferroelectrics. The dark emission appears at driving electric field amplitudes less than $10 \mathrm{kV} / \mathrm{cm}$, usually without visible light emission from the ceramic surface ${ }^{4-6}$. The current pulse in dark mode has a duration less than $0.5 \_\mathrm{s}$ at a current density amplitude $\leq 1 \mathrm{~A} / \mathrm{cm}^{2}$. The bright mode, which is accompanied by visible light emission ${ }^{7}$, requires driving electric field higher than 10 $\mathrm{kV} / \mathrm{cm}$. The current density in this mode can reaches hundreds of $\mathrm{A} / \mathrm{cm}^{2}$, and the current pulse may last tens of microseconds ${ }^{8}$. Recent investigations showed that, in the bright mode, strong electron emission occurs from the surface discharge plasma formed on the ceramic surface near the edges of the front electrode pattern ${ }^{9}$. This plasma has a density of $\sim 10^{12} \mathrm{~cm}^{-3}$, an electron temperature of $2-3 \mathrm{eV}$, and consists mostly of the materials of the ferroelectric ceramics and the front electrode ${ }^{10}$. The nature of the dark emission, however, is still unclear. Angadi et $a l^{4}$ and Shanon et $a l^{6}$. explain the electron emission in this mode by polarization switching, while Boscolo and $\mathrm{Cialdi}^{5}$ consider the field 
emission mechanism from tripple junctions at the edges of the patterned fron electrode, which is not strong enough for the ignition of the surface discharge.

Cathodes based on the effect of ferroelectric emission were successfully used in several experimental setups with applied magnetic field ${ }^{11,12,13,14,15}$. Indeed, ferroelectric cathodes are able to produce uniform electron beams with kiloampere currents and low beam divergence, without any delay of the beam with respect to the accelerating voltage application and without vacuum deterioration ${ }^{16}$. These features make ferroelectric cathodes very promising for powerful microwave devices like gyrotrons ${ }^{11,13}$, magnetrons ${ }^{14}$, and TW tubes ${ }^{15}$, which are usually operated under moderate accelerating fields (less than $50 \mathrm{kV} / \mathrm{cm}$ ). Ferroelectric cathodes might also be good candidates for a cathode-neutralizer for ion or Hall thrusters due to their ability to supply electron current with densities up to several $\mathrm{A} / \mathrm{cm}^{2}$, with long lifetime and without gas feeding. Alternatively, the ferroelectric cathode might supply charge along the channel of segmented electrode Hall thruster, thereby controlling the voltage drop, which in the same way as surface electrode function ${ }^{17,18,19}$. All of the applications cited above require the operation of ferroelectric cathodes in a magnetic field. However, to our knowledge, the behavior of the ferroelectric emission in magnetic field has not yet been studied. Accordingly, the first results of a study of ferroelectric cathode operation in a transverce magnetic field are presented here.

The ferroelectric samples used in these experiments were PZT ceramics type APC-850 (_ $=1750)$ supplied by American Piezo Ceramics, Inc. The disc samples with a diameter of $38 \mathrm{~mm}$ and a thickness of $2 \mathrm{~mm}$ were covered by solid rear and striped front electrodes made of copper, which were affixed to the samples with a conducting glue. 
The strips of the front electrode have a width of $1 \mathrm{~mm}$ with opening of $1 \mathrm{~mm}$ between them. The total active area had a diameter of $20 \mathrm{~mm}$. The front electrode was grounded, while a negative driving pulse was applied to the rear electrode. The rectangular driving pulse had a duration of $500 \mathrm{~ns}$ and was supplied by a pulse generator built using a double pulse forming network scheme. The amplitude of the driving pulse can vary from 0.5 to $25 \mathrm{kV}$ with a the repetition rate up to $1 \mathrm{kHz}$. The driving voltage and driving current were measured by Tektronix $\propto$ high voltage probe and Pearsonø Rogovski Coil, respectively.

The ferroelectric cathode was mounted on an iron core of a solenoidal magnetic coil. The diameter of the core was $50 \mathrm{~mm}$. The magnetic field at the front surface of the sample can reach up to $6 \mathrm{kGs}$. The nonunifromity of the magnetic field along the active area was less than $\pm 2.5 \%$ according to measurements by FD Bello gaussmeter. A grounded output grid with a transparency of $87 \%$ was placed at a distance of $4.4 \mathrm{~mm}$ from the front surface. The full setup was placed in a vacuum chamber pumped down to $\sim 3 \times 10^{-6}$ Torr.

Visible light emission from the surface was observed by Andorø I-Star ICCD camera. The image intensifier of this camera had an increased sensitivity in near-UV range, while the $\mathrm{CCD}$ chip was cooled down to $-16^{\circ} \mathrm{C}$. In fact, the camera worked in a photon counting regime, that allowed registration of images with ultra-low intensities. In the bright emission mode, no extracting electric field was applied. The parameters of the surface discharge plasma formed in this mode were measured by a cylindrical Langmuir probe placed at $5.6 \mathrm{~mm}$ from the output grid $(10 \mathrm{~mm}$ from the front surface of the sample). Electrons emitted from the cathode in dark mode were collected by a biased collector. The collector had a diameter of $27 \mathrm{~mm}$ and was placed at $8 \mathrm{~mm}$ from the 
sample surface in order to collect all electrons, taking into account the fringing of the solenoidal magnetic field outward from the core.

The dark emission mode was realized at driving pulse amplitudes about $1.7 \mathrm{kV}$, which corresponds to driving electric field of $8.5 \mathrm{kV} / \mathrm{cm}$. The emission current appeared almost simultaneously with the application of the driving pulse, and had a duration of $\sim 350-400$ ns. No ion current higher than $100 \_$A was registered by the negatively biased collector, either with or without magnetic field application. Thus, we expect that a surface plasma did not form.

However, the dark emission process was found not to be completely dark . Under maximal image amplification we observed diffuse light emission from the ceramic surface between the front electrode strips. The emission becomes visible during the rising of the driving pulse, namely at 20-30 ns from the beginning of the pulse having a rise time of $\sim 70 \mathrm{~ns}$. It reaches the maximal intensity in about $80-100 \mathrm{~ns}$ and then decreases gradually up to $800-900 \mathrm{~ns}$. The application of a transverse magnetic field higher than 1 kGs leads to significant decrease of the light intensity and to a delay of the light appearance. Images obtained at the same time delay from the beginning of the driving pulse are shown in Fig. 1 for the case of $B=0$ (a) and for $B=3.3 \mathrm{kGs}$ (b).

Note that the features of images in the dark mode presented here differ from images of surface discharge observed in the bright emission mode ${ }^{7}$. The emission does not have the typical pattern of separate discharge trees, but is rather diffuse and covers almost all ceramic surface between the strips. The only region in the middle between the strips, at the null of the tangential electric field, is darker. Such a diffusive light emission is typical for the pre-flashover phase of the surface discharge ${ }^{20}$. Moreover, the observed 
inhibition of the dark emission in magnetic field is also similar to the surface flashover $^{21}$. The inhibition of the dark emission is also seen from the decrease in the electron current collected by the positively biased collector (see Fig.2).

The obtained results are in qualitative agreement with the model of the dark emission suggested by Boscolo and Cialdi ${ }^{5}$. However, it appears here that electrons might be emitted not only from triple junctions at the edges of the strips due to field emission, but also from ceramic surface between the strip due to secondary electron emission caused by avalanching electrons. Electrons in these avalanches do not cause surface plasma formation for some reasons (like low avalanche current or low average electron energy, which might be insufficient for keeping required rates of ionization and neutral desorbtion). However, these avalanches can lead to sufficient surface charging, as reported in Ref. 5.

The input of electron avalanches into the dark emission current is also confirmed by estimations based on the model of electron avalanche ${ }^{22}$. The influence of the transverse magnetic field should be visible when the electron gyroradius $r_{c}=v_{e} m_{e} c / e B$ will be comparable with the mean free path of electrons along the surface. This condition is realizes when $B \sim 1 \mathrm{kGs}$, which agrees well with the observed threshold magnetic field influence (see Fig.2).

On the other hand, in the bright emission mode, the application of the magnetic field leads to increase of the plasma density of the surface discharge. In Fig 3 the ion saturation current density, measured by a Langmuir probe, is shown versus the magnetic field. One can see that, at the driving pulse amplitude of $U_{d r}=8.5 \mathrm{kV}$ and $B \sim 5 \mathrm{kGs}$, the measured current is almost twice the current without magnetic field. The higher the 
driving pulse amplitude, the lower the threshold at which the magnetic field causes the increase of the ion saturation current and the intensity of the visible light emission from the surface plasma. This effect of the magnetic field on the bright emission mode might be explained by the magnetization of electrons, which would cause an increase in the residence time of electrons in the layer of desorbed neutrals near the ceramic surface. The longer residence time would then result in the increase of the ionization, similarly to the most types of gas discharges in magnetic field.

This work was supported by the New Jersey Commission of Science and Technology, and by the DOE under contract DE-AC02-76-CH03073. 

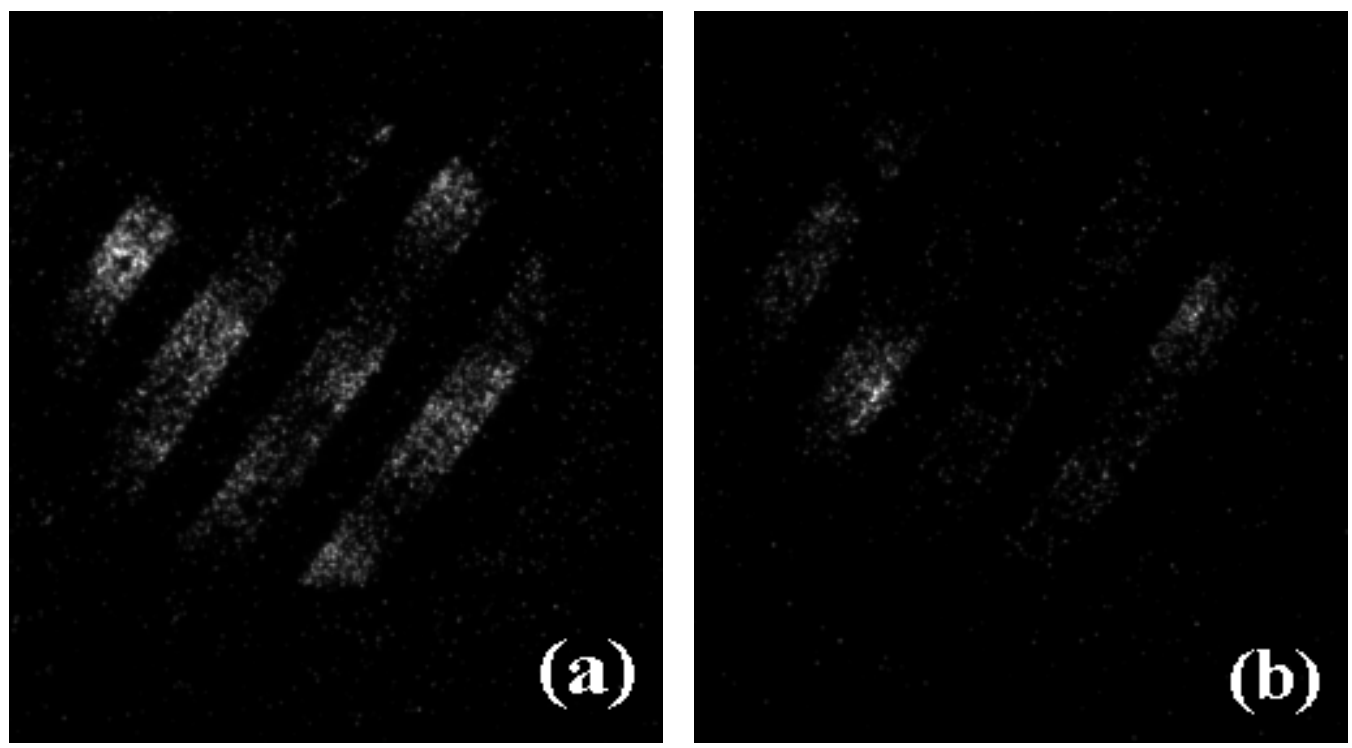

Fig. 1. Images of the surface of ferroelectric cathode in "dark" emission mode at $B=$ 0 (a) and at $B=3.3 \mathrm{kGs}(\mathrm{b})$. The driving pulse amplitude is $1.7 \mathrm{kV}$. The frame duration is $50 \mathrm{~ns}$, the delay from the beginning of the driving pulse is $50 \mathrm{~ns}$. 


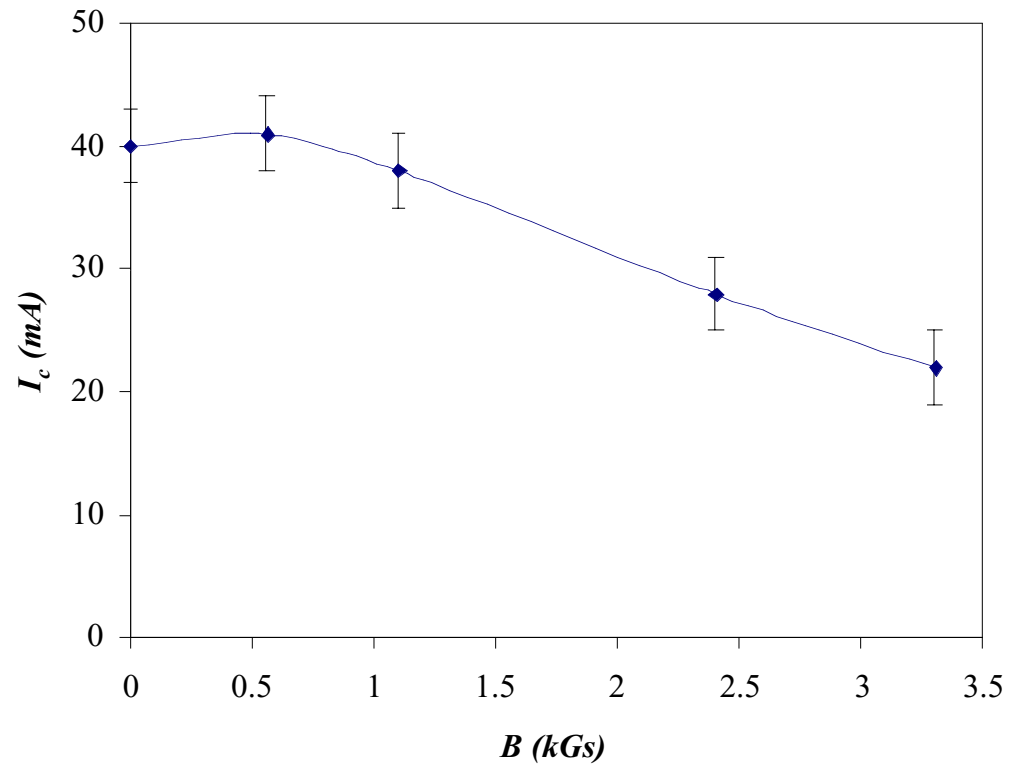

Fig. 2. The electron current $I_{c}$ measured by the biased collector versus applied magnetic field $B$. The bias voltage is $+50 \mathrm{~V}$. 


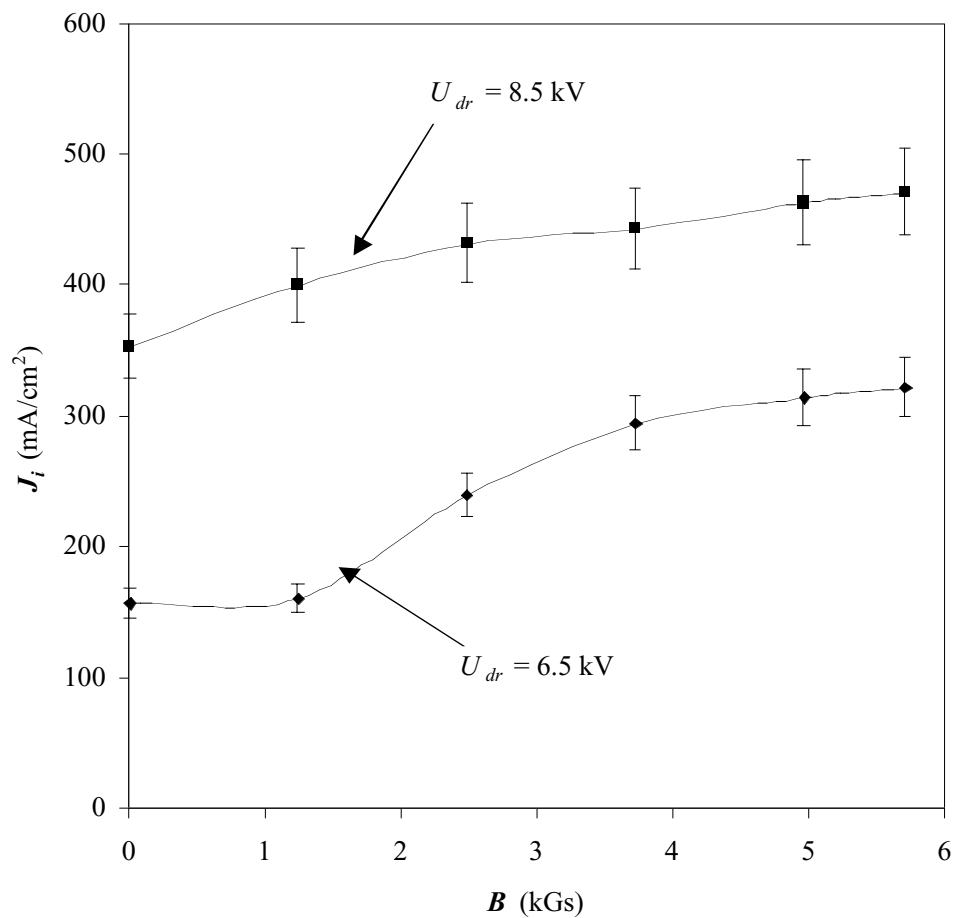

Fig. 3. The ion saturation current density $J_{i}$ versus the applied magnetic field $B$, for different driving pulse amplitudes $U_{d r}$. 
${ }^{1}$ H. Gundel, H. Riege, J. Handerek, and K. Zioutas, CERN/PS/88-66(AR)

${ }^{2}$ G. Rosenman, D. Shur, Ya. E. Krasik, and A. Dunaevsky, J. Appl. Phys. 88, 6109 (2000).

3 D. Shur, G. Rosenmann, J. Phys. D: Appl. Phys. 32, L29 (1999).

${ }^{4}$ D. N. J. Shannon, P. W. Smith, P. J. Dobson, and M. J. Shaw, Appl. Phys. Lett. 70, 1625 (1997).

5 I. Boscolo and S. Ciadi, J. Appl. Phys. 91, 6125 (2002).

6 M. Angadi, O. Auchiello, A. R. Krauss, and H. W. Gundel, Appl. Phys. Lett. 77, 2659 (2000).

${ }^{7}$ Ya. E. Krasik, A. Dunaevsky, and J. Felsteiner, J. Appl. Phys. 85, 7946 (1999).

8 A. Dunaevsky, Ya. E. Krasik, J. Felsteiner, and S. Dorfman, J. Appl. Phys. 85, 8474 (1999).

9 A. Dunaevsky, Ya. E. Krasik, J. Felsteiner, and S. Dorfman, J. Appl. Phys. 85, 8464 (1999).

10 A. Dunaevsky, K. Chirko, Ya. E. Krasik, J. Felsteiner, and V. Bershtam, J. Appl. Phys. 90, 4108 (2001).

11 M. Einat, E. Jerby, and G. Rosenman, Appl. Phys. Lett. 79, 4097 (2001).

12 D. Shur, G. Rosenman, Ya. E. Krasik, and R. Advani, J. Phys. D: Appl. Phys. 31, 1375 (1998).

13 R. Advani, J. P. Hogge, K. E. Kreischer, W. J. Mulligan, R. J. Temkin, G. R. Kirkman, B. Jiang, and N. Reinhard, IEEE Trans. Plasma Sci. 26, 1347 (1998). 
14 Ya. E. Krasik, A. Dunaevsky, J. Felsteiner, A. Krokhmal, C. Leibovich, A. Rosenberg, I. Schnitcer, and J. Shiloh, IEEE Trans. Plasma Sci. 28, 1642 (2000).

15 J. D. Ivers, D. Flechner, C. Golkowski, G. Liu, J. A. Nation, and L. Schachter, IEEE Trans. Plasma Sci. 27, 707 (1999).

16 A. Dunaevsky, Ya. E. Krasik, J. Felsteiner, and A. Sternlieb, J. Appl. Phys. 90, 3689 (2001).

17 Y. Raitses, L. A. Dorf, A. A. Litvak, and N. J. Fisch, J. Appl. Phys. 88, 1263 (2000).

18 N. J. Fisch, Y. Raitses, L. A. Dorf, A. A. Litvak, J. Appl. Phys. 89, 2040 (2001).

19 Y. Raitses, D. Staack, and N. J. Fisch, paper IEPC-01-060, $27^{\text {th }}$ International Electric Propulsion Conference, Pasadena, California, USA, (2001).

20 C. R. Li and T. S. Sudarshan, IEEE Trans. Elec. Ins. 2, 483 (1995).

${ }^{21}$ R. Korzekwa, F. M. Hermann, G. Krompholz, and M. Kristiansen, IEEE Trans. Plasma Sci. 17, 612 (1989).

22 A. S. Pillai and R. Hackam, J. Appl. Phys. 53, 2983 (1982). 


\section{External Distribution}

Plasma Research Laboratory, Australian National University, Australia

Professor I.R. J ones, Flinders University, Australia

Professor J oão Canalle, Instituto de Fisica DEQ/IF - UERJ , Brazil

Mr. Gerson O. Ludwig, Instituto Nacional de Pesquisas, Brazil

Dr. P.H. Sakanaka, Instituto Fisica, Brazil

The Librarian, Culham Laboratory, England

Library, R61, Rutherford Appleton Laboratory, England

Mrs. S.A. Hutchinson, JET Library, England

Professor M.N. Bussac, Ecole Polytechnique, France

Librarian, Max-Planck-Institut für Plasmaphysik, Germany

J olan Moldvai, Reports Library, MTA KFKI-ATKI, Hungary

Dr. P. Kaw, Institute for Plasma Research, India

Ms. P.J . Pathak, Librarian, Insitute for Plasma Research, India

Ms. Clelia De Palo, Associazione EURATOM-ENEA, I taly

Dr. G. Grosso, Instituto di Fisica del Plasma, Italy

Librarian, Naka Fusion Research Establishment, J AERI, J apan

Library, Plasma Physics Laboratory, Kyoto University, J apan

Research Information Center, National Institute for Fusion Science, J apan

Dr. O. Mitarai, Kyushu Tokai University, J apan

Library, Academia Sinica, Institute of Plasma Physics, People's Republic of China

Shih-Tung Tsai, Institute of Physics, Chinese Academy of Sciences, People's Republic of China

Dr. S. Mirnov, TRINITI, Troitsk, Russian Federation, Russia

Dr. V.S. Strelkov, Kurchatov Institute, Russian Federation, Russia

Professor Peter Lukac, Katedra Fyziky Plazmy MFF UK, Mlynska dolina F-2, Komenskeho Univerzita, SK-842 15 Bratislava, Slovakia

Dr. G.S. Lee, Korea Basic Science Institute, South Korea

Mr. Dennis Bruggink, Fusion Library, University of Wisconsin, USA

Institute for Plasma Research, University of Maryland, USA

Librarian, Fusion Energy Division, Oak Ridge National Laboratory, USA

Librarian, Institute of Fusion Studies, University of Texas, USA

Librarian, Magnetic Fusion Program, Lawrence Livermore National Laboratory, USA

Library, General Atomics, USA

Plasma Physics Group, Fusion Energy Research Program, University of California at San Diego, USA

Plasma Physics Library, Columbia University, USA

Alkesh Punjabi, Center for Fusion Research and Training, Hampton University, USA

Dr. W.M. Stacey, Fusion Research Center, Georgia Institute of Technology, USA

Dr. J ohn Willis, U.S. Department of Energy, Office of Fusion Energy Sciences, USA

Mr. Paul H. Wright, Indianapolis, Indiana, USA 
The Princeton Plasma Physics Laboratory is operated by Princeton University under contract with the U.S. Department of Energy.

\author{
Information Services \\ Princeton Plasma Physics Laboratory \\ P.O. Box 451 \\ Princeton, NJ 08543
}

Phone: 609-243-2750

Fax: 609-243-2751

e-mail: pppl_info@pppl.gov

Internet Address: http://www.pppl.gov 